(2) Open Access Full Text Article

ORIGINAL RESEARCH

\title{
Amoxicillin and Risk of Hearing Loss: Analysis of Reported Cases Submitted to the WHO Global Database
}

This article was published in the following Dove Press journal: Drug, Healthcare and Patient Safety

\author{
Mulugeta Russom (D) \\ Aziza Afendi (iD' \\ Amon Solomon \\ Ghebrenegus (1D) ${ }^{1,2}$ \\ 'Eritrean Pharmacovigilance Centre, \\ National Medicines and Food \\ Administration, Asmara, Eritrea; ${ }^{2}$ Biet- \\ Mekae Community Hospital, Asmara, \\ Eritrea
}

Background: Penicillins have never been associated with any form of hearing disorders. The Eritrean Pharmacovigilance Centre recently received two cases of hearing disorder (including one case of deafness) following the intake of amoxicillin capsules. This study was conducted to assess the causal link between amoxicillin and deafness.

Methods: Data mining was carried out in the WHO global database of individual case safety reports, VigiBase, and the Austin Bradford-Hill criteria were used to assess causality.

Results: A total of 94 cases of 'hearing disorders' related to amoxicillin were retrieved from VigiBase. Of these, 49 (52.1\%) were reported as "deafness," and amoxicillin was marked as the sole suspected drug in 18 and the only drug administered in 13 cases. In the rest of the deafness cases $(n=31)$, amoxicillin was concurrently administered with other drugs and reported as co-suspected. The median time to onset was three days and the outcome was marked as recovered (14), recovering (2), not recovered (16) and unknown (17). In five cases, deafness resolved following the withdrawal of amoxicillin.

Conclusion: There appears a causal association between amoxicillin and hearing loss that requires further substantiation with better epidemiologic studies.

Keywords: amoxicillin, hearing disorder, deafness, VigiBase

\section{Introduction}

Penicillins in general have never been associated with any form of hearing disorders or ototoxicity. Hawkins et al have defined ototoxicity as,

the tendency of certain therapeutic agents and other chemical substances to cause functional impairment and cellular degeneration of the tissues of the inner ear, and especially of the end-organs and neurons of the cochlear and vestibular divisions of the eight cranial nerve. ${ }^{1}$

Amoxicillin, in the penicillin family, is an antibiotic which is principally used for the treatment of infections caused by susceptible Gram-negative and Gram-positive bacteria. $^{2}$ Hearing disorder is not mentioned in the summary of product characteristics (SPC) of amoxicillin approved by the European Medicines Agency, 3,4 Medicines and Healthcare Products Regulatory Authority of the UK, ${ }^{5,6}$ US-FDA, ${ }^{7,8}$ and the National Medicines and Food Administration of Eritrea. ${ }^{9}$ However, amoxicillin has previously been associated with vertigo and/or dizziness. ${ }^{10}$

Recently, two cases of hearing disorders associated with the use of amoxicillin $500 \mathrm{mg}$ capsules (in previously healthy patients) were received by the Eritrean
Correspondence: Mulugeta Russom Eritrean Pharmacovigilance Centre, National Medicines and Food Administration, Asmara, Eritrea Tel +0029I-7I97450

Email satiswt@gmail.com 
Pharmacovigilance Centre. This study was therefore conducted to evaluate the causal association of amoxicillin and hearing loss using data extracted from the WHO global database of individual case safety reports (ICSRs), VigiBase. ${ }^{11}$

\section{Methods}

\section{Study Design and Data Source}

This was a descriptive assessment of amoxicillin and the risk of hearing disorders by mining data from VigiBase. ${ }^{11}$ VigiBase is the world's largest database of its kind with over 20 million ICSRs (as of March 2019) submitted from 136-member states since the establishment of the WHO Program for International Drug Monitoring in 1968. This databank is developed and maintained by the Uppsala Monitoring Centre (UMC), Sweden. Data mining on VigiBase was carried out on March 17, 2019 with search criteria: "amoxicillin" as drug substance and "hearing disorder" as MedDRA reaction term. For this study, the higher form of hearing loss reported as "deafness" was further analyzed. Cases of congenital deafness were excluded from this assessment to minimize confounders.

Reaction outcome, disproportionality measure (information component - IC value), de-challenge and rechallenge information, and other relevant variables were retrieved using VigiLyze. VigiLyze is a tool developed for data mining and analysis on VigiBase. Disproportionality of the drugadverse reaction (ADR) pair is measured by IC value. ${ }^{12,13}$ A positive IC value is "a traditional threshold which indicates that a drug-ADR pair is reported more often than expected based on all reports in VigiBase," thus showing a statistical signal. Retrieved information was exported to an Excel spreadsheet for further descriptive analysis.

A literature search on the association of amoxicillin and hearing disorders was also made on Google Scholar, PubMed, Medline, and other search engines using the following search criteria: "amoxicillin"; "hearing loss"; "deafness"; "ototoxicity"; "hearing disorder"; "hearing impairment"; and "tinnitus." Labeledness was also assessed by checking summary of product characteristics (SPCs) of amoxicillin approved by checking stringent authorities like European Medicines Agency, Medicines and Healthcare Products Regulatory Authority of the UK and US-FDA.

\section{Case Assessment}

Austin Bradford-Hill criteria were used to assess causality. ${ }^{14}$ Hill's criteria employ temporality, the strength of association, consistency and specificity, dose-response relationship, experimental evidence, biological plausibility, analogy, and coherence of the association as guidelines.

\section{Results}

Since 1977, a total of 94 cases of hearing disorders related to amoxicillin are retrieved from the WHO global database of ICSRs. In $55.3 \%$ of these cases $(n=52)$, the reaction was reported as "deafness." Forty-nine of the cases were further analyzed as three cases of congenital deafness were excluded from the analysis. The reported reaction terms were deafness (42), deafness bilateral (3), deafness transitory (2), conductive deafness (1), and deafness unilateral/deafness neurosensory (1). The IC value for the 42 deafness cases was found to be negative $\left(\mathrm{IC}_{025}=-1.82\right.$ and $\left.\mathrm{IC}=-1.35\right)$. The cases were reported from 17 countries, mainly from the USA (13), Australia (10), and the UK (7).

Sex was documented in all but three cases and $61.2 \%$ were females. Age was reported in 36 of the deafness cases; of which 14 (39\%) were below 50 with a median of 55 years. Amoxicillin was reported as the sole suspected drug in 18 of the cases and it was the only administered drug in 13 cases. In the rest of the cases $(n=31)$, amoxicillin was concurrently administrated with other drugs and reported as co-suspected. Gentamycin, metronidazole, and nitrofurantoin were the top reported co-administered drugs with amoxicillin. Moreover, erythromycin, azithromycin, and clarithromycin were coreported with amoxicillin in three cases each.

Time to reaction onset of deadness following the use of amoxicillin was reported in 19 of the cases and the median was found to be three days (range: 1 to 18 days). In 16 cases, the outcome of deafness was marked as recovered or recovering while in the remaining 33 cases either it was not recovered (16) or unknown (17). In five cases, deafness abated following the withdrawal of amoxicillin. Details of the 13 cases of deafness that are suspected to be encountered with the sole administration of amoxicillin are summarized in Table 1. In two of these cases, deafness resolved following discontinuation of the suspected drug, amoxicillin. Reaction outcome was reported as "recovered" in five cases, "not recovered" in three cases and "unknown" in the remaining five.

\section{Discussion}

In the cases where time to onset is documented, deafness was encountered shortly following the administration of amoxicillin capsule/tablet. In the majority of the deafness cases associated with amoxicillin, other drugs were 
Table I Summary of Cases of Deafness Associated with the Sole Administration of Amoxicillin Retrieved from WHO Global Database, VigiBase

\begin{tabular}{|c|c|c|c|c|c|c|c|c|c|}
\hline $\begin{array}{l}\text { Case } \\
\text { No. }\end{array}$ & Sex & $\begin{array}{l}\text { Age } \\
\text { (Years) }\end{array}$ & $\begin{array}{l}\text { Dose } \\
(\mathrm{mg})\end{array}$ & $\begin{array}{l}\text { Route of } \\
\text { Administration }\end{array}$ & Indication & Co-Reported Reactions Terms & Outcome & $\begin{array}{l}\text { Dechallenge } \\
\text { Information }\end{array}$ & $\begin{array}{l}\text { Time } \\
\text { to } \\
\text { Onset } \\
\text { (Days) }\end{array}$ \\
\hline I. & $\mathrm{F}$ & 16 & $\begin{array}{l}500 \mathrm{mg} \\
\mathrm{BID}\end{array}$ & PO & Tonsillitis & - & Recovered & Positive & 2 \\
\hline 2. & $\mathrm{~F}$ & & - & - & - & Parosmia | Ageusia & $\begin{array}{l}\text { Recovered } \\
\text { with } \\
\text { sequelae }\end{array}$ & - & - \\
\hline 3. & $\mathrm{~F}$ & 77 & - & - & Premedication & $\begin{array}{l}\text { Chest injury | Chest pain | Seizure | Skin } \\
\text { abrasion | Insomnia | Limb injury | } \\
\text { Prescribed overdose | Road traffic } \\
\text { accident | Stress }\end{array}$ & - & - & - \\
\hline 4. & $\mathrm{~F}$ & - & - & Other & - & $\begin{array}{l}\text { Condition aggravated | Emotional } \\
\text { disorder }\end{array}$ & Unknown & - & - \\
\hline 5. & $\mathrm{~F}$ & 6 & - & - & $\begin{array}{l}\text { Pharyngitis } \\
\text { streptococcal }\end{array}$ & $\begin{array}{l}\text { Adjustment disorder | Anaemia | } \\
\text { Blindness | Cellulitis | Phlebitis | } \\
\text { Staphylococcal infection | Stevens- } \\
\text { Johnson syndrome }\end{array}$ & - & - & 1 \\
\hline 6. & M & 29 & I g daily & PO & - & - & Recovered & - & 4 \\
\hline 7. & $\mathrm{~F}$ & 53 & $\begin{array}{l}500 \mathrm{mg} \\
\text { daily }\end{array}$ & PO & - & Vomiting | Vertigo | Tinnitus & Unknown & - & 1 \\
\hline 8. & $\mathrm{~F}$ & - & - & - & - & $\begin{array}{l}\text { Visual impairment | Thinking abnormal | } \\
\text { Amnesia }\end{array}$ & Unknown & - & - \\
\hline 9. & - & - & - & $\mathrm{PO}$ & $\begin{array}{l}\text { Infective otitis } \\
\text { externa }\end{array}$ & Dizziness | Nausea & Recovered & Positive & - \\
\hline 10. & $\mathrm{~F}$ & 47 & $3 \mathrm{~g}$ daily & PO & $\begin{array}{l}\text { Cystitis, } \\
\text { unspecified }\end{array}$ & Tinnitus & $\begin{array}{l}\text { Not } \\
\text { recovered }\end{array}$ & - & 10 \\
\hline 11. & $\mathrm{~F}$ & 53 & $\begin{array}{l}750 \mathrm{mg} \\
\text { daily }\end{array}$ & PO & $\begin{array}{l}\text { Chronic } \\
\text { sinusitis }\end{array}$ & $\begin{array}{l}\text { Nephritis | Acute kidney injury| Pyrexia | } \\
\text { Rash }\end{array}$ & Recovered & - & - \\
\hline 12. & $\mathrm{~F}$ & 31 & $\begin{array}{l}750 \mathrm{mg} \\
\text { daily }\end{array}$ & PO & 0465 & Ataxia | Muscle twitching & $\begin{array}{l}\text { Not } \\
\text { recovered }\end{array}$ & - & - \\
\hline 13. & $\mathrm{~F}$ & 82 & $\begin{array}{l}\text { 6DF } \\
\text { daily }\end{array}$ & $\mathrm{PO}$ & - & - & $\begin{array}{l}\text { Not } \\
\text { recovered }\end{array}$ & - & 7 \\
\hline
\end{tabular}

Abbreviations: M, male; F, female; BID, twice daily; PO, per oral.

concurrently taken. Thus, the case is difficult to attribute only to amoxicillin. However, there were 13 cases that developed deafness following the sole intake of amoxicillin in which the association was very specific; i.e. that a single drug was associated with a single reaction.

Clinically similar cases of deafness associated with amoxicillin were reported to the WHO global database of ICSRs from different parts of the world; making the association consistent. As the assessment of hearing disorders in preclinical trials is not usually a requirement for practicality reasons, there is no evidence that associates deafness with amoxicillin in animal studies. However, in one preclinical trial of ceftazidime, a broad-spectrum beta-lactam third-generation cephalosporine, a reversible middle ear inflammation with minor ototoxicity had been observed in chinchilla. ${ }^{15}$ In addition, the availability of cases of positive dechallenge can also be considered as experimental evidence. Therefore, the plausible temporal association, documentation of positive dechallenge in some cases, and specificity and consistency of the association strengthen the causal link. 
The possible biological mechanism by which amoxicillin causes deafness or hearing loss is unknown. However, druginduced ototoxicity or deafness can result from "a unique susceptibility of the injured tissue to the drug, accumulation of the drug within the organ or a combination of both factors. ${ }^{10}$ In addition, it was suggested that

inner ear injury may result from reversible inhibition of normal physiological functions, such as endolymph formation, which if inhibited for prolonged periods of time results in degeneration of tissue dependent upon the particular physiological function. Direct toxic effects on the sensory end organs (i.e. hair cells) also play a role in drug induced toxicity. ${ }^{10}$

The strength of association was weak as the IC value was negative. This shows that either the reaction is very rare or might be masked by other commonly reported reactions related to amoxicillin like allergic or hypersensitivity reactions. Other Hill's criteria such as coherence, analogy, and dose-response relationship were found to be non-applicable.

Therefore, the plausible temporal association, consistency of the cases, specificity of the association, the occurrence of a severe form of hearing loss following the sole intake of amoxicillin, and its reversibility solely after the withdrawal of amoxicillin (positive dechallenge) in some of the cases seem to support a causal association.

On the other hand, the causal association of hearing loss with amoxicillin had several confounding factors. The natural process of aging might be a contributory factor to the hearing disorder. The fact that several cases were below the age of 50, and that deafness was reversible in about half of the cases, only partially rules out the contribution of aging. In a few patients, drugs well known to be ototoxic, such as gentamycin, erythromycin, clarithromycin, and azithromycin, were co-reported; these on their own could cause the reaction. Furthermore, amoxicillin was indicated for upper respiratory tract and ear infections in some cases, which could be another unmeasured confounder. This study also had several limitations. Primarily, the cases are suspected or reported by health-care professionals and thus, could not be confirmed by the researchers. Moreover, this study had several unmeasured or uncontrolled confounders that would negatively affect the causation which could lead to exposure or outcome misclassification bias. For example, a few $(n=5)$ patients with reported deafness were taking amoxicillin for ear infection, which could be a confounding factor by indication. In addition, as the cases were spontaneously reported, we cannot quantify the risk of hearing loss associated with amoxicillin due to a lack of denominator data. Further, it is important to note that this safety signal is a hypothesis and needs to be substantiated with stronger epidemiologic study designs.

In conclusion, this assessment shows that there seems a causal relationship between amoxicillin and risk of hearing loss. Although this might not be a life-threatening condition, "it can have a negative impact on communication and healthrelated quality of life, with significant vocational, educational and social consequences."16 Taking the high global consumption of amoxicillin into account, the event might be very rare. Health-care professionals should therefore be aware of the potential risk and refer such cases to audiology clinics for further diagnosis and better management. Further, manufacturers and health-care professionals should advise consumers to immediately seek medical attention if they experience any signs of hearing disorders while using amoxicillin. This article can also be a lesson that even old drugs that have been on the market for decades can sometimes pose new potential risks.

\section{Abbreviations}

EMA, European Medicines Agency; IC, Information Component; ICSR, Global Individual Case Safety Reports; MedDRA, Medical Dictionary for Regulatory Activities; MHRA, Medicines and Healthcare Products Regulatory Authority; SPC, Summary of Product Characteristics; UMC, Uppsala Monitoring Centre; US-FDA, United States Food and Drug Administrations.

\section{Data Sharing Statement}

Sharing of individual information about the cases is not allowed as per the EU data privacy policy regulation but aggregated data can be provided upon reasonable request from the corresponding author.

\section{Disclaimer}

The association presented in this manuscript is those of the authors and does not represent the opinion of the WHO or the Uppsala Monitoring Centre, Sweden.

\section{Ethics Approval and Consent to Participate}

As the study uses retrospective data from the WHO global database, ethical approval and consent for participation are not required for authorized professionals of countries participating in the WHO program for international drug monitoring. 


\section{Acknowledgments}

We would like to thank Dr. Amanuel Habtemichael, ENT clinic, Orotta national referral hospital for his valuable input in reviewing the manuscript. All reporters are also highly appreciated for their vigilance.

\section{Author Contributions}

MR conceived the idea and AA analyzed the data. All authors contributed to data analysis, drafting or revising the article, have agreed on the journal to which the article will be submitted, gave final approval of the version to be published, and agree to be accountable for all aspects of the work.

\section{Disclosure}

The authors declare that they have no competing interests.

\section{References}

1. Hawkins JE. Drug ototoxicity. In: Keidel WD, Neff WD, editors. Handbook of Sensory Physiology. Berlin: Springer-Verlag; 1976:707-748.

2. America Society of Health-System Pharmacists. American hospital formulary services drug information. 1984.

3. European Medicines Agency. Summary of characteristics of Amoxicillin $500 \mathrm{mg} / 25 \mathrm{mg}$ capsules and $125 / 5 \mathrm{ml} / 250 \mathrm{mg} / 5 \mathrm{ml}$ powder for suspension. Available from: https:/www.ema.europa.eu/en/docu ments/referral/amoxil-article-30-referral-annex-iii_en.pdf. Accessed September 18, 2019.

4. European Medicines Agency. Summary of characteristics of Amoxicillin $500 \mathrm{mg}$ capsule.

5. Medicines and Healthcare Products Regulatory Agency. Summary of characteristics of Amoxicillin $500 \mathrm{mg}$ capsule. Aurobindo Pharma Milpharm Ltd; Available from: https://www.medicines.org.uk/emc/pro duct/526/smpc. Accessed September 18, 2019.
6. Medicines and Healthcare Products Regulatory Agency. Summary of characteristics of Amoxicillin 250mg/500mg/1gm capsule. Wockhardt UK Ltd; Available from: https://www.medicines.org.uk/ emc/product/526/smpc. Accessed September 18, 2019

7. United States Food and Drug Administration. Prescribing information of Amoxicillin $250 / 500 \mathrm{mg}$ capsules and $125 \mathrm{mg} / 5 \mathrm{ml}, 200 \mathrm{mg} / 5 \mathrm{ml}, 250 \mathrm{mg} /$ $5 \mathrm{ml}, 400 \mathrm{mg} / 5 \mathrm{ml}$ powder for suspension. Available from: https://www. drugs.com/ppa/amoxicillin.html. Accessed September 18, 2019.

8. United States Food and Drug Administration. Prescribing information of Amoxicillin $250 / 500 \mathrm{mg}$ capsules and $125 / 250 \mathrm{mg} / 5 \mathrm{ml}$ powder for suspension. Available from: https://www.accessdata.fda.gov/drugsatfda docs/label/2008/050760s11,050761s11,050754s12,050542s25lbl.pdf. Accessed September 18, 2019.

9. Eritrea Medicines and Food Administration. Summary of characteristics of Amoxicillin 500/250 mg capsule, Azel Pharma.

10. Bisht M, Bist SS. Ototoxicity: the hidden menace. Indian J Otolaryngol Head Neck Surg. 2011;63(3):255-259. doi:10.1007/ s12070-011-0151-8

11. Uppsala Monitoring Center. WHO global individual case safety reports database. Available from: https://www.who-umc.org/vigi base/vigibase/. Accessed March 17, 2019.

12. Bate A, Lindquist M, Edwards IR, et al. A Bayesian neural network method for adverse drug reaction signal generation. Eur $J$ Clin Pharmacol. 1998;54(4):315-321. doi:10.1007/s002280050466

13. Norén GN, Bergvall T, Ryan PB, Juhlin K, Schuemie MJ, Madigan D. Empirical performance of the calibrated self-controlled cohort analysis within temporal pattern discovery: lessons for developing a risk identification and analysis system. Drug Saf. 2013;36 (1):107-121. doi:10.1007/s40264-013-0095-x

14. Hill A. Environment and disease: association or causation? Proc Royal Soc Med. 1965;58:295-300. doi:10.1177/003591576505800503

15. Brown OE, Wright CG, Edwards LB, et al. The ototoxicity of ceftazidime in the chinchilla middle ear. Arch Otolaryngol Head Neck Surg. 1989;115(8):940-942. doi:10.1001/archotol.1989.01860320050017

16. Knight KR, Kraemer DF, Neuwelt EA. Ototoxicity in children receiving platinum chemotherapy: underestimating a commonly occurring toxicity that may influence academic and social development. $J$ Clin Oncol. 2005;23:8588-8596. doi:10.1200/JCO.2004.00.5355
Drug, Healthcare and Patient Safety

\section{Publish your work in this journal}

Drug, Healthcare and Patient Safety is an international, peer-reviewed open-access journal exploring patient safety issues in the healthcare continuum from diagnostic and screening interventions through to treatment, drug therapy and surgery. The journal is characterized by the rapid reporting of reviews, original research, clinical, epidemiological and post-marketing surveillance studies, risk management, health literacy and educational programs across all areas of healthcare delivery. The manuscript management system is completely online and includes a very quick and fair peer-review system. Visit http://www.dovepress.com/testimonials.php to read real quotes from published authors. 